\title{
Stefan Haack, Theorie des öffentlichen Rechts
}

\section{Philipp Siegert}

\section{OpenEdition \\ Journals}

Édition électronique

URL : http://journals.openedition.org/ifha/9682

DOI : 10.4000/ifha.9682

ISSN : 2198-8943

Éditeur

IFRA - Institut franco-allemand (sciences historiques et sociales)

\section{Référence électronique}

Philipp Siegert, "Stefan Haack, Theorie des öffentlichen Rechts », Revue de l'IFHA [En ligne], Date de recension, mis en ligne le 28 octobre 2018, consulté le 24 septembre 2020. URL : http:// journals.openedition.org/ifha/9682 ; DOI : https://doi.org/10.4000/ifha.9682

Ce document a été généré automatiquement le 24 septembre 2020.

(C)IFHA 


\title{
Stefan Haack, Theorie des öffentlichen Rechts
}

\author{
Philipp Siegert
}

\section{RÉFÉRENCE}

Stefan Haack, Theorie des öffentlichen Rechts, Tübingen : Mohr Siebeck, 2017, 93 p., $24 €$ 
Dans sa "théorie du droit public», le professeur de droit Stefan Haack (Université Viadrina de Francfort-surl'Oder) se propose d'aborder un vaste sujet en moins de cent pages, raison pour laquelle on peut qualifier cet ouvrage «d'essai », comme le fait l'auteur (p. 20). $\mathrm{Au}$ fil de la lecture, le contraste entre l'étendue du sujet et la brièveté du texte apparaît de moins en moins surprenant : il s'agit en effet pour l'auteur de défendre le concept de droits publics subjectifs (subjektive öffentliche Rechte), introduit dans la science juridique allemande par Georg Jellinek (1892) et débattu depuis. S. Haack en fait le point de départ de son argumentation pour démontrer que seule la consécration de ces droits ferait d'un État un État de droit.

Sans entrer dans les détails du concept des droits publics subjectifs, on peut retenir (et l'auteur incite le lecteur à le faire) qu'ils permettent à une personne d'amener l'État devant le juge, c'est-à-dire à s'opposer à des décisions administratives par voie judiciaire si elle estime être lésée dans ses droits. Par conséquent, l'argument ou plutôt la thèse centrale de S. Haack est que le droit public et finalement l'État de droit tout court ne peuvent être appréhendés qu'à partir du conflit entre le citoyen et l'État se déroulant devant un juge et d'après des normes juridiques fondées sur ces droit publics subjectifs (p. 3). Il entend ainsi distinguer le droit public des autres types de normativités qui peuvent guider les actions de l'État pour aboutir à une théorie et à une conception - qui rappelle Hans Kehlsen - strictement juridique des normes qui composent le droit public (par exemple p. 15, 26). Outre le moment conflictuel, c'est cette délimitation qui représente la pierre angulaire de la conception du droit public défendue par l'auteur (p. 31).

L'approche adoptée par S. Haack produit des résultats intéressants, et son essai vaut d'être lu à plus d'un titre. L'auteur renvoie régulièrement à l'histoire du droit; les pages 32-42 livrent ainsi un aperçu particulièrement synthétique et instructif de l'évolution conceptuelle du droit public en Allemagne. Il oppose notamment les droits publics subjectifs au droit public objectif (une différenciation qu'il qualifie de "fondamentale », p. 45), ces deux conceptions conduisant selon lui à deux systèmes de contrôle très différents des agissements de l'État: seul le premier pourrait garantir l'existence de l'État de droit (p. 52, 64), le deuxième étant compatible avec plus ou moins tous les types d'États, y compris les dictatures (p. 40-41). Cette garantie de l'État de droit par la consécration des droits publics subjectifs découle notamment du fait que ce seraient précisément ces droits qui garantiraient au citoyen de revendiquer « que l'administration ne limite l'étendue de leur liberté qu'en se fondant sur et suivant les exigences des lois » (p. 43). Suite aux modalités de l'accès au juge administratif, l'auteur identifie d'ailleurs une judiciarisation des liens entre État et citoyens qui serait 
théoriquement plus durable en Allemagne fédérale qu'en France (le nexus entre atteinte aux droits individuels et capacité d'ester en justice étant moins étroit, p. 51).

S. Haack s'intéresse en particulier à la figure du juge dans la troisième partie de son essai (p. 61-84), dans laquelle il tente de démêler une constellation qui pose pour ainsi dire «traditionnellement » un problème dogmatique : si l'État et le citoyen s'opposent en cour, il appartient au juge de trancher ; ce dernier est donc placé au-dessus des deux parties litigieuses, mais il est en même temps fonctionnaire et donc « membre » d'une de ces parties (c'est-à-dire de l'État). Ce raisonnement mène $\mathrm{S}$. Haack à aborder la question plus générale de l'existence du droit dans et par l'État et donc du caractère particulier de ce dernier : il est autant sujet du droit que structure porteuse du droit (comprenant les pouvoirs législatif et judiciaire). L'État (de droit) précède-t-il donc le droit ou est-ce l'inverse ? De manière élégante - mais sans trancher la question, car il déclare le droit public et l'État de droit indissociables l'un de l'autre -, S. Haack conclut que « le droit est la prémisse et l'État la justification » (p. 83).

Dans toutes les réflexions qu'il présente dans sa Théorie, S. Haack attribue au conflit judiciarisé (le litige devant un juge indépendant, mené et jugé d'après des normes strictement juridiques et garanties par des droits publics subjectifs) un rôle fondamental dans l'existence de l'État de droit - et en fait l'approche privilégiée pour concevoir ce dernier. Même s'il mobilise un concept élaboré il y a déjà plus de cent ans, son approche ainsi que son style d'écriture précis et concis sont tout à fait stimulants. L'essai de S. Haack entend contribuer aux débats de sa discipline dans les aires germanophones sur des questions absolument fondamentales, telles que l'existence même de l'ordre juridique (le "point de culmination" de toute réflexion du juriste, p. 24-25, 74). Le lecteur qui souhaite avoir un aperçu non seulement d'une des conceptions-clef du droit public en Allemagne, mais également de son évolution et de l'état de l'art du débat scientifique trouvera dans ce petit livre une lecture fort instructive.

\section{INDEX}

Index chronologique : Époque contemporaine

Thèmes : Histoire du droit, Histoire des idées

\section{AUTEURS}

\section{PHILIPP SIEGERT}

IFRA-SHS, Francfort-sur-le-Main 